\title{
Bored of the rings (pages, texts, and emails)
}

\author{
Richard Casey, MD, FRCS
}

Community Urologist, Oakville, ON, Canada

Cite as: Can Urol Assoc J 2018;12(10):E438-9. http://dx.doi.org/10.5489/cuaj.5608

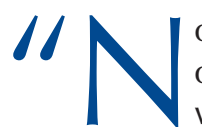
ot peanut butter again!" he remarked to his office mate. "I'm so sick of peanut butter sandwiches for lunch. I've had them EVERY day for the last 5 years!"

"You should ask your wife to make you something different," replies his friend.

"Wife? I make my own lunches!"

Sound familiar? Maybe not, but the practice of medicine can sometimes remind one of peanut butter, particularly after 30 years. It was time to do something to recharge my professional life. I chose New Zealand. Fortunately, I had a contact in Wellington. I'd also heard that a local urologist had spent some time on the island a few years ago and liked it. A urology colleague of mine had befriended a Kiwi while completing an oncology fellowship in Vancouver and connected me with Mr. Studd. Time to see if I could locum in New Zealand. The year was 2013, my 30th year as a community urologist.

Few of us get the chance to practice our skills outside of Canada. If you're lucky enough to visit another country and observe other urologists at work, you'll see that the core work is the same; it's everything around the surgical procedure and clinical work that's slightly different. My non-Canadian surgical experience consisted of two years in Texas when I was first starting out and a surgical course in Italy, where the anesthetist smoked in the hallway while we debated where to have lunch...oh, and yes, I learned how to insert an anti-incontinence device. New Zealand didn't have the food culture Italy had, but licensure wasn't particularly difficult and they were short urologists. I decided that I could cut a few months out of my Oakville practice and see how the Kiwis practice urology. Maybe my interest in erectile dysfunction (ED) and clinical trials might bring something different to the island? Think again. It is a general community urology experience similar to what we used to do in the 90s, before everyone subspecialized. Open prostates, even the occasional open kidney and pyeloplasty, are not uncommon. Prostates, stones, hematuria, and bladder cancer fill the clinics.

"I couldn't leave my practice for one, two, or three months..." I hear you thinking that, but I have some bad news for you. You can, and your absence will barely be noticed. That's actually good news if you think about it, but I digress.

Wellington is the capital of New Zealand, the southernmost city on the North Island. Landing in an airport that was decorated as Middle Kingdom thanks to Peter Jackson's success, the city reminded me of the 1960s. No tall buildings and plenty of older structures (theaters, old banks, etc.), the city appeared to be stuck in another era. Fantastic place, but I'm not a travel agent so I'll focus on the urology experience. Did I mention that there wasn't a Starbuck's?

New Zealand has a public healthcare system and allows physicians to provide private healthcare outside the public hospitals. Many of the larger cities have a public hospital and a private one close by, where most urologists split their time. Patients can move freely between the two, although I've seen little of that. Patients wait a bit longer for their procedures than they might in Canada, but their expectations are different. All referrals to the urology department are triaged by the department. Less urgent, primary care-type consults are returned with a comment and a suggestion. Urgent cases are seen immediately. Some things are not handled in the public system, like ED after failing oral agents or infertility. I'm not sure where these patients are seen, or if they ever are. My position was only in the public hospital.

I arrived in Wellington on a Sunday and started work Monday in theatre. After a quick tour and introductions, I was given my theatre schedule: two ureteroscopies, a transurethral resection of the prostate, and a circumcision. They apologized for the list, wondered if it was too much, and then were perplexed while I laughed for a half-hour. I introduced myself to my patients as the "Canadian" and they were all comfortable with meeting their surgeon 10 minutes prior to their procedure.

I had stopped laughing by the time morning tea was ready. A slightly longer break between morning cases allowed us to sit and socialize, have some tea and toast. I asked if we could just move through the list so I could finish earlier and go for a bike ride. "No, we'll finish at 4," was my answer. The work expanded to fill the time and for the first few weeks, I struggled with my operating day anxiety before I realized that there was no reason to hurry. 
All good-sized hospitals have house officers and I was lucky enough to have an R5 in urology and a junior registrar. Once a week we rounded and all the ward work was handled by house staff. In addition, while I was on call frequently, most of the after-hours work was handled by house officers, including torsion, ureteral stones, and urinary retention. My R5 was an outstanding resident and he taught me plenty. I taught him caution and exposed him to a slightly different approach to just about every procedure we did together.

My second day in Wellington was my clinic day. Wellstaffed, most patients had significant urological issues and I was paced to see one patient every 20-30 minutes. The urology nurse apologized for the busy clinic day, as the R5 was in theatre and I was alone. I would have to struggle through the list, 12 patients in all. "What about the afternoon?" I asked.

"That's busy as well. You have six flexible cystos. Have I said something funny or is it my accent?" she said, looking my puzzled face.

"No," I answered. "I'm just happy."

A typical week consisted of two theatre days and four half-day clinics where we also did cystoscopies and transrectal ultrasound biopsies. One day a week was for paperwork. I left New Zealand with all my charts complete. Do not show this to Health Records in Oakville!

Weekly M\&M meetings, an hour going over X-rays and discussing cases, and a fairly relaxed schedule made it not only a good learning experience for me, but a reminder that there can be considerable joy practicing urology.

I had brought my family along and after seeing Wellington, they headed out to Queenston, the ski capital of New Zealand, located in the South Island. Imagine Banff — like amenities with skiing similar to Grey Rocks in Quebec, but considerably warmer. Back in Wellington, I played squash, explored the city, and continued to practice urology at a pace that allowed me to enjoy my work even more. The local urologists made me feel at home, but did not feel responsible to entertain me. They are used to having locum physicians from other parts of New Zealand help out when someone is gone.

The head of the department, who has since retired, asked me if I knew the famous Sender Herschorn. He had completed a fellowship with Sender in the late 80s at Sunnybrook and couldn't say enough nice things about him. I told him that I had heard the name but that the only famous urologist I knew from Toronto was Laurie Klotz.

In the middle of our stay, there was a significant earthquake that repositioned the road I had used to drive to work! Amazing how blasé Kiwis seem to be about quakes. We were to experience two more during our stay. One had been enough for me!

While I noticed small, subtle nuances to practice in New Zealand, the quality was outstanding and the consultants first-rate. I've since worked in Hamilton, Napier, and Nelson. I've learned something new each time. I've also learned a lot about winemaking, developed a taste for flat whites and long blacks, and made a few friends along the way.

Would I suggest you consider New Zealand as a place to locum. Definitely not. It's cold in the winter (goes down to 2 degrees in some places), windy in Wellington, and there's no ice hockey (just rugby and cricket). They drive on the wrong side of the road and, most importantly, I haven't finished going there for my yearly get away! The takeaway is simple. A good way to examine your skill set and recharge your professional life is to expose it to other professionals and their patients and see how it holds up. I've been wellserved by the education I've received here and have been proud to represent Canadian community urologists in the middle kingdom!

Correspondence: Dr. Richard Casey, Community Urologist, Oakville, ON, Canada; drrcasey@gmail.com 